\title{
Mucoepidermoid Carcinoma of the Head and Neck: Clinico-Pathologic Study of 12 Cases
}

\section{RANJAN AGRAWAL, MITHILA BISHT, PARBODH KUMAR}

\section{ABSTRACT}

Introduction: Mucoepidermoid carcinoma (MEC), one of the most common salivary gland malignancies, but it is rare in children. MEC occurs mainly in the parotid gland, followed by the minor salivary glands. Palate being the second common site.

Aim: The present study was undertaken with the aim of studying the clinico-pathological presentations as well as the histopathological grading of head and neck mucoepidermoid carcinoma.

Materials and Methods: During the 2 year retro-prospective study a total of 12 cases diagnosed as Mucoepidermoid carcinoma in the head and neck region in a tertiary care hospital were included in the present study. Clinic-pathological presentations of these patients were recorded. Histological grading was done as per the Armed Forces Institute of Pathology criteria.
Results: Out of the 12 cases, 8 were males and 4 females with the age ranging from 18 to 65 years; the average age being 40.08 years. Four patients each presented with ulcer and ill-defined swelling and 2 each, as growth and cyst. Histopathologically 5 patients were low grade, 6 as intermediate grade and 1 as high grade.

Conclusion: Prognosis of patients with MEC greatly depends on the tumour stage as well as the histologic grade of the lesion. Typical treatment involves surgical excision for low grade lesions and surgical excision with elective neck dissection in the ipsilateral neck followed by adjuvant radiation therapy for higher grade lesions. Grade II tumours are treated similarly to grade III since, even though the behaviour resembles grade I tumours, they possess a predilection for nodal metastasis as in grade III lesions.

\section{INTRODUCTION}

Mucoepidermoid carcinoma (MEC) is the commonest salivary gland malignancy. MEC comprises of a mixture of cells, including the mucin producing, squamous (epidermoid), and the intermediate ones. It represents a distinct type of tumour. After the parotid glands, MEC can be located in the palate, retromolar area, floor of mouth, buccal mucosa, lips, tongue, lacrimal glands, bronchi, nasal mucosa, oesophagus, maxilla, mandible, liver, cervix, penis and anus [1-4]. A series of 12 cases describing MEC with varying clinical presentations and their histopathological grading is being presented in this article.

Mucoepidermoid carcinoma (MEC) has an incidence of approximately 3/1,000,000 people with slightly higher predilection in males, whereas few authors indicate a slight female predilection. Salivary gland carcinomas comprise only $3-5 \%$ of all head and neck malignancies. Overall, MEO accounts for $2.8-15.5 \%$ of all salivary gland tumours; $1-10 \%$ of all major salivary gland tumours and $6.5-41 \%$ of minor salivary gland tumours. Mucoepidermoid carcinomas can occur in any age groups, but are most common in the middle age (35-65 years of age) with an average age of 47 years $[1,5]$. In the present study the average age was 40.08 years.

\section{MATERIALS AND METHODS}

This was a retro-prospective study carried out from January 2013 to December 2014 for the duration of two years. All the cases of surgery from head and neck region received in the Department of Pathology, Rohilkhand Medical College and Hospital, Bareilly during the study period were included for the study. Detailed data such as age, sex, site of lesion and clinical presentation were collected. Routine Haematoxylin and Eosin staining was performed. Special stains and Immunohistochemistry were applied as and when required. The microscopic findings were tabulated and the Armed Forces Institute of Pathology (AFIP) grading system was used to assign the grade to individual cases.

\section{RESULTS}

A total of 12 cases of Mucoepidermoid carcinoma of head and neck region were analysed during the study period. The 


\begin{tabular}{|c|c|c|l|l|l|}
\hline S.No. & Age (Yrs) & Sex & Site & Presentation & C/F \\
\hline 1 & 18 & F & Right Parotid & Cystic & Pain \\
\hline 2 & 55 & F & Left Post auricular & Growth & $\begin{array}{l}3 \times 2 \mathrm{~cm} \text { oval swelling } \times \text { 3 months; Discharge x5 days. No inflammation. } \\
\text { Non-Tender. Immobile }\end{array}$ \\
\hline 3 & 18 & M & Right Pre-auricular & Swelling & $2 \times 1.5 \mathrm{~cm}$. \\
\hline 4 & 35 & M & Left Pre-auricular & Cyst & Near Tragus \\
\hline 5 & 55 & M & Left lower eyelid & Ulcer & Ulcer \\
\hline 6 & 18 & M & Right Parotid & Swelling & Serous discharge \\
\hline 7 & 30 & F & Soft Palate & Swelling & Non-tender irregular swelling since childhood. \\
\hline 8 & 33 & M & Soft Palate & $\begin{array}{l}\text { Ulcero-Proliferative } \\
\text { growth }\end{array}$ & Pain on swallowing. \\
\hline 9 & 60 & M & $\begin{array}{l}\text { Left Posterior } \\
\text { Pharyngeal wall }\end{array}$ & Growth & Difficult swallowing and pain throat x 15 days. Tender, Reddish \\
\hline 10 & 65 & M & Soft Palate & Ulcer & Difficult swallowing since 5 months; Non-tender, Fixed \\
\hline 11 & 32 & F & Hard Palate & Swelling & $2 \times 3$ cm swelling; Firm to hard, Non-tender \\
\hline 12 & 62 & M & Right Cheek & Ulcer & \\
\hline [Table/Fig-1]: Showing clinical presentation of patients with Mucoepidermoid carcinoma.
\end{tabular}

[Table/Fig-1]: Showing clinical presentation of patients with Mucoepidermoid carcinoma.

\begin{tabular}{|c|c|c|c|c|c|c|c|l|l|}
\hline Case No. & Age (Yrs) & Sex & Intracystic (2) & Neural (2) & Necrosis (2) & Mitosis (3) & Anaplasia (4) & Total (13) & AFIP Grade \\
\hline 1 & 18 & F & 2 & 0 & 0 & 3 & 0 & 5 & Intermediate \\
\hline 2 & 55 & F & 0 & 0 & 0 & 3 & 0 & 3 & Low \\
\hline 3 & 18 & M & 2 & 0 & 0 & 3 & 0 & 5 & Intermediate \\
\hline 4 & 35 & M & 2 & 0 & 0 & 3 & 0 & 5 & Intermediate \\
\hline 5 & 55 & M & 0 & 0 & 0 & 3 & 0 & 3 & Low \\
\hline 6 & 18 & M & 2 & 0 & 0 & 0 & 4 & 6 & Intermediate \\
\hline 7 & 30 & F & 0 & 0 & 0 & 0 & 4 & 4 & Low \\
\hline 8 & 33 & M & 0 & 2 & 2 & 0 & 4 & High \\
\hline 9 & 60 & M & 0 & 0 & 0 & 3 & 0 & 3 & Low \\
\hline 10 & 65 & M & 2 & 0 & 0 & 3 & 0 & 5 & Intermediate \\
\hline 11 & 32 & F & 2 & 0 & 0 & 3 & 0 & 5 & Intermediate \\
\hline 12 & 62 & M & 0 & 2 & 2 & 0 & 0 & 4 & Low \\
\hline
\end{tabular}

[Table/Fig-2]: Showing microscopic findings, points and grading of patients with Mucoepidermoid carcinoma.

Intracystic =Intracystic component $<20 \%$

Neural $=$ Neural invasion

Mitosis $=$ Mitotic figures $>4 / 10 \mathrm{HPF}$

age ranged from 18 to 65 years with an average age of 40.08 years. There were eight males and four females. Out of these 5 were present in and around the parotid region, 3 on the soft palate and 1 each on the hard palate, lower eyelid, cheek and posterior pharyngeal wall. The clinical presentation is shown in [Table/Fig-1]. The presentation was as ulcer in 4 cases, illdefined swelling in 4, growth in 2 and as cyst in 2 patients. The duration of symptoms varied from 15 days to 5 years. two cases presented with discharging ulcer, one with oozing of serous fluid and the other viscous discharge. The microscopic findings and the grade were tabulated [Table/Fig-2,3]. Each case diagnosed as MEC was selected for grading into low, intermediate and high based on the microscopic findings including percentage of intracystic component, necrosis, National Journal of Laboratory Medicine. 2016 Apr, Vol 5(2): 12-16 neural invasion, mitosis and anaplasia as per the AFIP grading [Table/Fig-4]. Out of these, 5 cases were graded as low, 6 as intermediate and 1 as high grade lesions. Problematic cases were subjected to special stains including Periodic Acid Schiff (PAS) and Immunohistochemistry including pan-Cytokeratin, CEA and S-100 markers. There were varied results of all the markers in different cases. Pancytokeratin was positive in 7 cases; CEA showed good positivity in 2 and focal positivity in 3 cases; S-100 in 2 cases only. PAS showed good positivity in 2 cases and focal positivity in 3 cases.

\section{DISCUSSION}

MEC can have varied presentation since, it can arise from any site of salivary tissue. The usual presentation is in the 

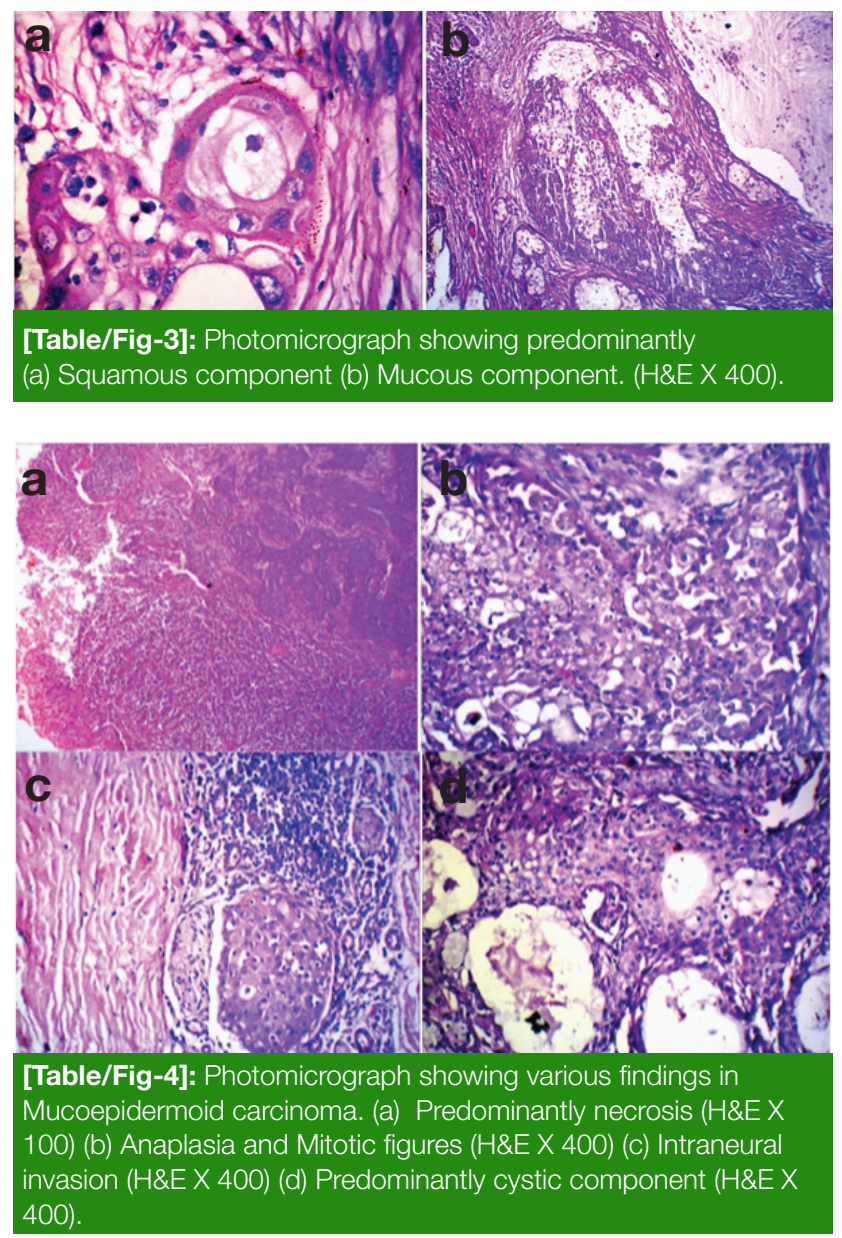

form of a solitary painless and enlarging mass especially in the salivary glands, most commonly the parotid gland being affected. Within the aero-digestive tract there are a number of areas with higher concentrations of minor salivary glands. Hard palate and retromolar trigone are more predisposed to MEC as they have the highest concentration of minor salivary glands. Sublingual glands are the smallest of the major salivary glands and are being characterised by being unencapsulated. Involvement of the major salivary glands and tongue causes difficulty in the sensation alongwith pain and difficulty in deglutition. Lesions within the oral cavity present as a nodule with a smooth outer surface [6].

The exact aetiology of MEC is still controversial. However, a gene translocation at $\mathrm{t}(11 ; 19)(\mathrm{q} 21 ; \mathrm{p} 13)$ has been detected in more than $80 \%$ of MEC cases which encodes a transcription factor CREB (CAMP response element-binding protein) $[7,8]$.

The differential diagnosis depends on the tumour appearance. For well circumscribed lesions, benign mixed tumour, Warthin tumour and Adenoid cystic carcinoma should be considered. For infiltrative lesions Adenoid cystic carcinoma, Lymphoma (NHL) and metastasis (especially metastatic squamous cell carcinoma to intra-parotid nodes), Adeno squamous carcinoma, Necrotising sialometaplasia and Poorly differentiated adenocarcinoma should be thought of. In palate both reactive and neoplastic lesions should be considered. In children, the commonest is palatal space abscess after pulpal necrosis. Mucocoele is a fluctuant reactive lesion, with transparent blue swelling including mucin. Vascular malformations like haemangiomas are differentiated by clinical examination and imaging. At times, Neurofibroma and schwannoma may be observed as compressible or firm asymptomatic pinkish nodules unless there is secondary trauma $[5,6,9]$.

Histopathology demonstrates three cell types-"epidermoid" cells, "mucous producing" cells, and the "intermediate" cell type considered to be modified epithelial cells. These intermediate cells are present in the lining of several multicystic spaces with solid components within the same tumour mass. Presence of these cells provides a high degree of clue to the diagnosis of MEC even on FNAC. Keratinisation is rare and immunohistochemistry is not of much help in determining a diagnosis. Mucin cells can be identified on routine $\mathrm{H}$ and $\mathrm{E}$ staining and confirmed using mucicarmine, periodic acid-schiff, or alcian blue stains. In high-grade tumours the squamous cells are known to predominate whereas in low grade tumours the mucin producing cells are the chief cells observed. The high grade tumours are firm and show features of ulceration, resorption of bone and numbness of teeth adjacent to the tumour cells. On the contrary, the low grade tumours are soft and can be compressed easily [10].

An ideal grading system accurately predicts outcome, is helpful in planning management, is applicable to all sites in which a tumour can be seen, has simple criteria, is quick and time efficient and reproducible with minimal inter and intra-observer variability. Ideally, it is difficult to have an ideal grading system especially in malignancy of salivary gland due to lack of sufficient sample size. It is not surprising to observe high grade features in otherwise low-grade tumours and vice-versa. Both pathologists and clinicians should be aware of these variants. Mucoepidermoid tumours are graded histologically into low grade, intermediate grade and high grade based on a constellation of features including cystic component, border, mitoses, anaplasia, and perineural and angiolymphatic invasion. The three most popular grading systems are: the Armed Forces Institute of Pathology (AFIP) grading system, Modified Healey system, and the Brandwein system [11-14]. Grading of mucoepidermoid carcinoma is not without flaws. One clear deficiency in all systems, particularly the point based schemes is the application difficulty. The widely used Brandwein grading system is a revision of the AFIP, evolved since the original AFIP system was not strict enough and need was felt for these tumours to be treated more aggressively for better survival rates. Grade I lesions are the least aggressive and most likely to act locally and grade III lesions are the most aggressive [5]. Grade II lesions fall in the intermediate range and have characteristics of both. It is a 
point to note that usually MEC that does not show aggressive features are considered as low grade. However, just a few of the findings may make the tumour of a high grade, which drastically affects both the behaviour as well as the treatment and thus the prognosis [7].

Use of any grading system may be tiresome and subjective however use of a scheme rather than using an individual approach may have greater effect. Histopathological grading carries a good prognostic implication, but should be combined with the size of the tumour as well as the lymph node status for assessment of the final grading. The tumours of the intermediate category pose the greatest difficulty in determining the prognosis. As per the AFIP grading system these are clubbed with the high grade lesions whereas, as per the Brandwein system they fall into the low grade lesions [15-16]. Histopathological variants of MEC especially the sclerosing or the oncocytic types may pose difficulty in the grading system. Oncocytic variant may be considered to be a high grade tumour but may have a benign course [5]. Factors carrying a poor prognosis include - old age of patient, male sex, involvement of submandibular gland, extension of the tumour beyond the salivary glands, vascular invasion, presence of necrosis, increased mitosis and higher histopathological grade. Age more than 40 years, fixed tumours, T and N stage and histological grade are independent significant prognostic factors in patients with MEC. The staging of MEC of the head and neck depends on the site of tumour, while grading provides more specific details of the nature of the disease $[7,17,18]$.

Radiographic appearances mainly depend on grade, making pre-operative imaging important in planning and counseling. Ultrasound shows typically a well-circumscribed hypoechoic lesion standing out against the relatively hyperechoeic normal parotid gland. It is essential to image the cranial nerves with fat saturated post contrast T1 sequences to assess for perineural spread. The scan should also include the base of skull, cavernous sinus and inner ear. Findings on a CT-scan depend on the tumour grade. Low grade tumours have larger cystic components, lesser solid components, and rare calcifications. Grade III lesions are poorly circumscribed and show local infiltration with a solid appearance. Grade II lesions have a combination of both. MRI gives a better clarity to the soft tissue characteristics of the tumour and determines presence of any gross perineural invasion. Generally, grade I MEC have low T1 signal and high T2 signal owing to the higher cystic component; whereas grade III MEC show low T1 and T2 signal [19].

FNAC has a limited role in salivary gland malignancies and there is a high rate of error if used as the sole method of diagnosis. FNAC has proved to carry more specificity than sensitivity. False negativity rates for head and neck MEC has been reported to be around $43 \%$ even for low grade tumours [20-21].

National Journal of Laboratory Medicine. 2016 Apr, Vol 5(2): 12-16
Treatment of parotid MEC depends on the tumour grade and location: low grade are usually treated with wide local excision and preservation of the facial nerve, without the need for neck dissection or adjuvant radiotherapy. High grade usually requires complete parotidectomy, often with sacrifice of the facial nerve, neck dissection (as nodal metastases are common) and adjuvant radiotherapy. The tumour is dissected down to the periosteum to obtain adequate tumour-free margins. However, if there is any evidence of bony involvement, removal of a portion of the jaw is mandatory [22].

The reported overall five year survival for MEC ranges from 92 to $100 \%$ for low grade tumours, 62-92\% for intermediate grade tumours, and $0-43 \%$ for high grade tumours [22]. The controversy arises in the management of intermediate grade mucoepidermoid. There is a very high local recurrence rate for high grade tumours. MEC has a predilection for perineural spread, so a careful and long term follow-up is mandatory.

\section{CONCLUSION}

Mucoepidermoid carcinoma is an important salivary gland malignancy with a unique histopathology. The prognosis hinges greatly on not only the tumour stage, but also the histologic grade of the lesion. Involvement of palate by MEC and other similar tumours is extremely rare. These patients must be followed-up carefully and multidisciplinary treatment helps them. Grading in no other salivary gland malignancy is as important to prognosis and therapy as in MEC. Typical treatment involves surgical excision for low grade lesions and surgical excision with elective neck dissection in the ipsilateral neck followed by adjuvant radiation therapy for higher grade lesions. Grade II tumours are treated similarly to grade III since, even though the behaviour resembles grade I tumours, they possess a predilection for nodal metastasis as in grade III lesions.

\section{REFERENCES}

[1] Kim TS, Lee KS, Han J et-al. Sialadenoid tumors of the respiratory tract: radiologic-pathologic correlation. AJR Am J Roentgenol. 2001; 177(5):1145-50.

[2] Brookstone MS, Huvos AG. Central salivary gland tumours of the maxilla and mandible: a clinicopathologic study of 11 cases with an analysis of the literature. Journal of Oral and Maxillofacial Surgery. 1992; 50(3): 229-36.

[3] Agrawal R, Kumar P, Varshney R. Recurrent mucoepidermoid carcinoma of the left lower eyelid: a common tumor in a rare site. Indian J Pathol Microbiol. 2014; 57(2):351-52. doi: 10.4103/0377-4929.134752. PMID: 24943794

[4] Biswas J, Datta M, Subramaniam N. Mucoepidermoid carcinoma of the lower lid - report of a case. Indian J Ophthalmol. 1996;44:231-33.

[5] Seethala RR. An Update on grading of salivary gland carcinomas. Head Neck Pathol. 2009; 3(1): 69-77. Published online 2009 February 25. doi: 10.1007/s12105-009-0102. PMCID: PMC2807532

[6] Sengul F, Simsek S, Cakur B. Mucoepidermoid carcinoma in a minor salivary gland in a child, Case Reports in 
Dentistry, vol. 2013, Article ID 615948, 4 pages, 2013. doi:10.1155/2013/615948.

[7] Byrd SA, Spector ME, Carey TE, Bradford CR, McHugh JB. Predictors of recurrence and survival for head and neck mucoepidermoid carcinoma. Otolaryngol Head Neck Surg. 2013; 149(3):402-08. Published online 2013 May 21.

[8] Isayeva T, Said-Al-Naief N, Ren Z, Li R, Gnepp D, BrandweinGensler M. Salivary mucoepidermoid carcinoma: demonstration of transcriptionally active human papillomavirus 16/18. Head Neck Pathol. 2013;7(2):135-48.

[9] Guzzo M, Andreola S, Sirizzotti G, Cantu G. Mucoepidermoid carcinoma of the salivary glands: clinicopathologic review of 108 patients treated at the National Cancer Institute of Milan. Ann Surg Oncol. 2002; 9(7):688-95.

[10] Som PM, Brandwein MS. "Anatomy and pathology of the salivary glands," in Head and Neck Imaging, P.M. Som and H.D. Curtin. Eds; pp. 2448-2609, Mosby Elsevier, St Louis, Mo, USA, 2011.

[11] Goode RK, Auclair PL, Ellis GL. Mucoepidermoid carcinoma of the major salivary glands: clinical and histopathologic analysis of 234 cases with evaluation of grading criteria. Cancer. 1998;82(7):1217-24.

[12] Goode RK, El-Naggar AK . Lyon: IARC Press; 2005. Mucoepidermoid Carcinoma. WHO Organization Classification of Tumours. Pathology and Genetics of Head and Neck Tumours; p. 219-20.

[13] Batsakis JG, Luna MA. Histopathologic grading of salivary gland neoplasms: I mucoepidermoid carcinomas. Ann Otol Rhinol Laryngol. 1990; 99(10 Pt 1):835-38. [PubMed]

[14] Brandwein et al. Mucoepidermoid carcinoma. The American Journal of Surgical Pathology. 2001; 25(7): 835-45.

[15] Aro K, Leivo I, Makitie AA. Management and outcome of patients with mucoepidermoid carcinoma of major salivary gland origin: a single institution's 30-year experience. Laryngoscope. 2008;118(2):258-62. doi: 10.1097/MLG.0b013e31815a6b0b. [PubMed] [Cross Ref]

[16] Nance MA, Seethala RR, Wang Y, et al. Treatment and survival outcomes based on histologic grading in patients with head and neck mucoepidermoid carcinoma. Cancer. 2008;113(8):208289.

[17] Liu S, Ow A, Ruan M, Yang W, Zhang C, Wang L, Zhang C. Prognostic factors in primary salivary gland mucoepidermoid carcinoma: an analysis of 376 cases in an Eastern Chinese population. Int J Oral Maxillofac Surg. 2014;43(6):667-73. doi: 10.1016/j.jijom.2014.01.008. Epub 2014 Feb 23.

[18] Chen MM, Roman SA, Sosa JA, Judson BL. Histologic grade as prognostic indicator for mucoepidermoid carcinoma: a population-level analysis of 2400 patients. Head Neck. 2014; 36(2):158-63.

[19] Kashiwagi N, Dote K, Kawano K, Tomita Y, Murakami T, Nakanishi K, et al. MRI findings of mucoepidermoid carcinoma of the parotid gland: correlation with pathological features. $\mathrm{Br}$ J Radiol. 2012;85(1014):709-13. doi: 10.1259/bjr/55639432. Epub 2011 Sep 6. PMID: 21896663 PMCID: PMC3474098

[20] Jeong WJ, Park SJ, Cha W, Sung MW, Kim KH, Ahn SH. Fine needle aspiration of parotid tumors: diagnostic utility from a clinical perspective. J Oral Maxillofac Surg. 2013;71(7):1278-82.

[21] Tryggvason G, Gailey MP, Hulstein SL, Karnell LH, Hoffman HT, Funk GF, et al. Accuracy of fine-needle aspiration and imaging in the preoperative workup of salivary gland mass lesions treated surgically. Laryngoscope. 2013; 123(1):158-63.

[22] Ellis G, Auclair P, editors. Tumours of the salivary glands. Atlas of tumour pathology. No 17, $3^{\text {rd }}$ Series ed. Washington DC: Armed Forces Institute of Pathology; 1996.

\section{AUTHOR(S):}

1. Dr. Ranjan Agrawal

2. Dr. Mithila Bisht

3. Dr. Parbodh Kumar

\section{PARTICULARS OF CONTRIBUTORS:}

1. Professor, Department of Pathology, Rohilkhand Medical College Hospital, Bareilly, India.

2. Assistant Professor, Department of Pathology, Rohilkhand Medical College Hospital, Bareilly, India.

3. Professor and Head, Department of Pathology, Rohilkhand Medical College Hospital, Bareilly, India.

\section{NAME, ADDRESS, E-MAIL ID OF THE} CORRESPONDING AUTHOR:

Dr. Ranjan Agrawal,

Professor, Department of Pathology, Rohilkhand Medical College Hospital, Pilibhit Bypass Road, Bareilly, India.

E-mail: drranjan68@gmail.com

FINANCIAL OR OTHER COMPETING INTERESTS: None. 